\title{
The Future of Theory in the Study of Medical Sociology
}

\author{
Jimmy Ebi Eko \\ Department of Sociology, Faculty of Social Sciences, University of Calabar, Calabar, Nigeria
}

Email address:

jimmyeko25@gmail.com

\section{To cite this article:}

Jimmy Ebi Eko. The Future of Theory in the Study of Medical Sociology. International Journal of Sustainable Development Research. Vol. 3, No. 1, 2017, pp. 1-6. doi: 10.11648/j.ijsdr.20170301.11

Received: September 1, 2016; Accepted: January 12, 2017; Published: February 9, 2017

\begin{abstract}
Theorizing in medical sociology has been the core in the understanding of health problems, their emergence, pattern of spread and their tendency to disappear in due course. All health institutions and organizations rely on well-developed models, frameworks or paradigms to function effectively and achieve desired results. In contemporary societies, the endemicity, aetiology, transmission and the therapy of some health conditions such as HIV, cancer, obesity, hypertension, uterine fibroid, kidney failure, coronary health disease, malaria, diabetes mellitus, gall stone and others have not been thoroughly explained with the existing theories. Even among prevailing social problems which affect human health directly or indirectly, existing theories have not been able to diagnose them. Hence, there is a growing need for theorists, scholars and researchers to work symbiotically and synergistically to bring about stability, social equilibrium and positive change in the society.
\end{abstract}

Keywords: Theory, Medical Sociology, Health Problems, Social Equilibrium

\section{Introduction}

Theorizing in medical sociology has been the core in the understanding of health problems, their emergence, pattern of spread and their tendency to disappear in due course. Health care providers have been so reliant on theories and models to provide optimal health care services to their clients especially in the face of increasing complexity in human health needs. Even in research, the relevance of theory is overwhelming in that it helps in the synthesis, integration and interpretation of empirical findings which are often used to control social as well as health phenomena. Theorists and their postulations and assumptions have contributed substantially in virtually all aspect of human existence to carefully diagnosis the aetiology of human problems and guide in the process of proffering solutions to such problem. In today's contemporary societies, governments and organizations have recorded successes in averting certain health problems which have ravaged mankind and these successes have been attributed to the effort of theorists and their propositions. Even with the existence of some intractable health problems, theorists have devised a means to ensure that the vulnerable populations still live their normal healthy lives devoid of their illness state since the solution to provide cure is still farfetched. It has also become evident that the level of patronage of formal health institutions from the primary-totertiary has experienced a decline because people now try to understand the cause of their health problems and as such adopt a home remedy to the situation without the help of the health care professional. In another instance, people now see the need to adhere to societal norms, standards, principles, guidelines, concepts and regulations in order to stay healthy. All of these achievements are predominantly the concerted efforts of theorist in the sociology of health.

Nevertheless, inspite of these achievements, medical sociologists are still faced with numerous health challenges. Some of which their aetiology is unknown while others lack the therapeutic approaches to avert their endemicity even when their cause is known. Hence, the future of theory in the study of medical sociology cannot be overemphasized. This paper seeks to expound information on the achievements of medical sociology theorists, their challenges in contemporary societies and their panorama in future theorizing.

\section{Achievements of Theorists}

Theorists have achieved a lot over the past years especially in the area of finding permanent solutions to social and health problems. Some diseases have been eradicated, eliminated and controlled successfully with the sole effort of theorists. 
For instance, the germ theory have been the brain behind the eradication and amelioration of certain internationally notifiable diseases such as poliomyelitis, measles, small pox, malaria, tuberculosis, diphtheria, yellow fever, plaque, cholera, Ebola virus, etc. The discovery of their aetiology has also found ways to cure them. These diseases have been successfully eradicated in most developed countries of the world, but most developing countries still suffer some of these diseases for obvious reasons. The concept of the Germ theory has been helpful in the development of vaccine to control epidemics across states and countries [1]. Certain micro-organism can effectively be dealt with via the use of antibiotics, antiseptics and anti-bacterial agents which is also the contribution of the germ theory [1]. The multiple causation theory has been useful in understanding the dynamics of illnesses or diseases and their aetiology. Where the germ theory failed due to its one-germ-one-disease concept, the multiple causation theory was found to be a useful replacement. Commonly known non-infectious diseases such as hypertension, diabetes mellitus, cancer, obesity, heart failure, etc has been discovered not to have single causes, but rather their occurrences are due to a number of causes. Even if these non-infectious diseases have not been combated successfully, theorists have devised a framework to manage them. The witchcraft theory of disease causation have been a useful framework in understanding the low health seeking behviour of people especially in the rural settings and high patronage of diviners, spiritualists, sorceries and herbalists. Researchers have found out that certain illness and diseases have been attributed to witchcraft. The belief in witchcraft especially among Africans has jeopardized their effort to seek health care in formal health institutions and as a result exacerbates their health conditions. The ecological theory has been useful in understanding that extrinsic factors play major role in disease causation among humans.

Aside health issues, a lot of other social problems have been diagnosed to understand the intricacies of their occurrence as well as how they can be eradicated from the society. These social problems could directly or indirectly affect the health of the populace. One of such social problem is alcoholism. Theorists have developed models to explain the practice of excessive and habitual drinking patterns of people. The psycho-analytical and ecological theories have been useful in this regard. The social exchange theory has been useful to understand the practices of prostitution and social relationships. Even the way people dress, walk, talk, act and behave generally have been explained in divergent theories. The change in demographic structure have been explained and predicted in demographic theories such as the Malthusian theory and Warren Thompson theory of demographic transition. These theories have been useful in understanding the dynamics of population growth and socioeconomic development of countries [2]. The existence of government policies, rules, regulations, programmes and projects are products of theories and models put together by theorists who had the utmost intention to find solutions to prevailing problems in the society. Theories have equally been useful in the prediction of events and occurrences especially in the areas of population growth, epidemiological indices, life expectancy, crude death rate, birth rates and other demographics. The "ideal type bureaucracy" propose by Max Weber have been adopted widely in all health and social institutions and organizations. This has brought about division of labour, smooth execution of tasks and efficient delivery of services. Hence, the achievements of theorists in the study of health and other social problems are laudable and commendable. For instance, the eradication of the Ebola virus was successfully done via the underlying framework of theorists. Medical or health professionals rely on these paradigms to provide optimal care to their clients.

\section{Future of Theory in Studying Medical Sociology}

In today's world, there have been incessant outbreaks of diseases ravaging the economies of countries. Even for endemic diseases, like Zika virus in South America and malaria in Africa, the tendency to curb their spread have been possible but the eradication of these endemic diseases have been intractable. As earlier stated, theorists have helped the society to understand the aetiology of certain social and health problems but no therapeutic approach have been discovered. Under the context of this paper, each of these issues would be extensively discussed.

HIV (Human Immunodeficiency Virus) which has been discovered since 1981 is a worldwide epidemic that has led to hundreds of thousands of deaths. Although existing framework have been use to minimize its prevalence rate as well as improve the quality of life of people living with HIV/AIDS (PLWHA), different ART centers across the country still report new infections. Currently, there is no known cure for HIV and because of this, people are still vulnerable to contracting the virus except they adhere to its preventive measures. Also, HIV patients still experience a high level of stigma and discrimination in the society even with the high level of awareness reported in empirical studies $[3,4]$. Efforts of theorist so far have been to understand the dynamics of HIV occurrence, causation and spread, but its therapy is still highly anticipated to permanently avert the epidemic.

Malaria (also called Plasmodiasis) is another longstanding endemic disease that has been responsible for high rates of morbidity and mortality especially in sub-Saharan African countries and Nigeria. According to [5], malaria is responsible for 60 percent of outpatient consultation, 30 percent of hospital admission among children under five years, 30 percent of childhood deaths, 25 percent of deaths in children under one year, and 11 percent of maternal deaths. Government and non-governmental organizations have invested so much to fight the disease. However, their efforts so far have not been able to measure up with the proliferation of malaria parasites that infect his host. Just like the developed countries, Nigeria strongly awaits for a time when 
malaria would be averted completely. Even though its aetiology have been known with the help of the germ theory and others, governments, global bodies, agencies and the populace still anticipates for a permanent cure or therapy which existing theories have not been able to prove.

Obesity has become an emerging global health problem affecting individuals of both sexes. It begins from early childhood and advance to adult stage of development. Theorists have predicted that overweight persons are more likely to become obese in the future. According to existing literature, obesity is primarily caused by excessive eating (eating disorder) and physical inactivity (increase in sedentary lifestyle). This obviously indicates that the aetiology have been known with the help of aetiological theories. However, it has been recommended that overweight and obese persons should regulate their eating habits and engage in regular physical exercise. But today, scientists have discovered that obesity can lead to several other factors thereby exacerbating the health condition of sufferers. These factors include; cardiovascular diseases, cancer, stroke, dementia and others. This therefore throws a challenge to theorists to formulate a reliable framework that would be used as a working tool to control and avert obesity.

Diabetes mellitus, another non-communicable disease has affected over 415 million people globally, of which 14 million cases were reported in the African Region. Researchers and theorists have predicted that the figure would double by 2040. According to [6], Nigeria reported an estimated 1.56 million cases of diabetic patients in 2015. The current prevalence of Diabetes Mellitus in Nigeria is not known but it is estimates may likely be in the range from $8 \%$ $10 \%$ [7]. Three of the four types of diabetes are well recognized which include type 1 diabetes mellitus, type 2 diabetes mellitus and gestational diabetes. Type 2 diabetes mellitus is the commonly documented which accounts for about $90 \%-95 \%$ of all cases. With the use of the multiple causation theory, it has become increasing clear that diabetes mellitus is a syndromic health condition rather than just a disease. This has made the search for its cure or therapy difficult, even though several interventions have been approved to manage the condition.

Cancer has recently been responsible for increase rate of mortality in Nigeria and in other low and middle income countries. As Published by [8], statistics have shown that breast cancer, cervical cancer, prostrate cancer, colorectal cancer, liver cancer are the commonest types of cancer cases in Nigeria. Among these, breast and cervical cancer are the most common among women while prostrate cancer is among the men. From the foregoing, this disease seems far from eradication due to its low awareness level, lack of medical and diagnostic equipments and lack of facilities for care and treatment of canceric patients except scholars, clinicians and theorists rise to the course of finding an appropriate solution to tackle it. Another common health condition is the uterine fibroid (an abdominal growth that develops in the women's uterus). It is a gynecological problem among women of reproductive age (15-49 years) which has attendant adverse consequences on fertility and pregnancy outcome [9]. Available data showed that uterine fibroid ranges from $17.9 \%-26 \%$ in Nigeria as against $5-11 \%$ reported in Europe and United States [10]. This health condition has been a growing virulent disease or disorder in contemporary societies which has affected the health of young girls and women. Scientists and researchers have tried to under-study the aetiology of uterine fibroid but it dynamics and rapid occurrences especially among young girls is highly questionable and drives the curiosity of researchers. Hypertension which is widely regarded as a silent killer is a patho-physiological condition responsible for high rates of morbidity and mortality affecting several people, irrespective of age, gender and economic status. Hypertensive patients are also reportedly at risk for stroke, vascular disease, myocardial infraction and chronic kidney disease. Up till date, the primary type of hypertension has no known identifiable cause affecting about $90 \%$ of hypertensive patients. This means that the search for the aetiology of primary hypertension is still in progress.

Aside health, certain social problems have been a major problem in many societies, countries and regions. These social problems directly or indirectly affect health. One of such social problem ispoverty. The scourge of poverty has been a hoary problem that has adversely affected the life of people socially, economically, morally, politically, educationally and intellectually. People are predisposed to a lot of health conditions as a result of poverty. Poverty could give rise to other prevailing social problems such as teenage pregnancy, prostitution, malnutrition, insecurity, unemployment, deviance behaviour, crimes and others. Today, this scourge (poverty) grows increasingly day by day especially in populated regions. This account for why most Nigerians still live below the poverty line. Several government policies to tackle poverty were established, and prominent among them was the National Poverty Eradication Programme (NAPEP) which was established by the Obasanjo's administration. Divergent institutes and organizations were constituted to aid NAPEP achieve its objectives. However, concerted efforts towards combating poverty so far have been abortive. Increase in population growth, rapid urbanization, increase industrialization and increase migration and terrorism has inhibited the workability of these poverty fighting policies. Scholars all over are currently worried on the rising trend in the rate of poverty; Why is poverty increasing? What possible way can poverty be eradicated? These questions have been awaiting answers.

Unemployment is another major social phenomenon with untold consequences on poor families, youths and the disadvantaged population. The number of unemployed Nigerians is increasing on daily basis with no prospect of reducing in time to come. Nigeria's unemployment rate has increased from $10.4 \%$ in the fourth quarter of 2015 to $12.1 \%$ in the first quarter of 2016, while youth unemployment has equally increased from $14.46 \%$ to $16.39 \%$ in the first quarter of 2016 [11]. Theorists and economists have predicted that 
unemployment will double or triple if not tackle as soon as possible. Unemployment has led to the rise in crime waves such as terrorism, widespread poverty and youth restiveness across countries. This means that for these problems to be solved, unemployment must be dully addressed. The upsurge in unemployment is the concern of scholars and what possible framework to demolish it to the breast minimum is the concern of theorists.

The sudden emergence of baby factories couple with human trafficking are prominent social issue especially in Nigeria. Young girls are trafficked to reclusive environment and housed there as sex machines. Young boys are also recruited to get these girls pregnant and on the event that the pregnant girls deliver, the babies are sold to top politicians and business tycoons who use these babies for ritual purposes. On rare occasions, families may wish to adopt such babies as their foster child. The engagement in unprotected sexual intercourse, violation of human rights, increase in death of babies and young girls and its psychological effects on the young girls who are victims are perceived to be consequences of the practices of baby factories and human trafficking/trafficking of young girls and women. The question raised here is "how did baby factories emerge?"Has it affected the moral standards of the society? The existing apostles of morals/morality are yet to give an explanation of these social phenomena.

Climate change is another social issue of global concern. This is because it has affected virtually all aspect of human existence ranging from the mangrove forest, vegetation, marine environment, nutrition, weather change, depletion of the ozone layer, radiation, housing structure and infrastructures, technology, etc. Obviously, there is great concern to check climate change because its emergence has led to food insecurity, scarcity of natural resources, increase unemployment, outbreaks of diseases and others. Existing theories may have probably not envisaged this to be a social problem of concern. Teenage pregnancy is one major social problem in every social milieu. This singular phenomenon has led to increase rate of unwanted pregnancy, unsafe abortion and death of many young girls. In-school female adolescent often become school dropout when they become pregnant. The situation becomes worsen when cultures and traditions still promote the practice of early marriage for the girls which is predominant in the Northern part of Nigeria. Increase in the moral decadence may also have fuelled this problem. The ecological and social learning theories have been useful in explaining the aetiology of teenage pregnancy. However, its therapeutic approach is yet to be established.

Gayism and lesbianism are gradually becoming social phenomena in contemporary societies. Gayism is practiced by young boys and men while young girls and women indulge in the act of lesbianism. These practices have hampered the health and future prospects of young boys and girls. These practices are carried out by individuals from all social strata, spheres and milieus. The move to legalize Gayism and lesbianism is clearly an indication of its acceptance. Aside the fact that gayism and lesbianism practices have adverse consequences on the physical, social and psychology well being of individuals, it alters and disrupts the moral system of the society. Nigerian scholars, researchers and moralists inveigh against these practices.

The rampant use of illicit drugs has become a practice that seems intractable. People use illicit drugs for divergent reasons ranging from sexual pleasure, form of relaxation, addiction, peer influence/feel among others and probably to exert happiness at least for a while. For instance, tremadol which was mainly designed for therapeutic purpose is now used commonly as a sexual enhancer. Other individuals get addicted to cocaine, marijuana and cannabis and this has negative effect on them physically, psychologically and socially. As a result, the government of Nigeria have strive in its effort to curb these practices via the establishment of agencies like National Drug Law Enforcement Agency (NDLEA) to checkmate illegal drug consumption and trafficking, but efforts have not measure up to the rising phenomenon. People now engage in drugs trafficking to make ends meets and solely adopt it as a source of livelihood. The reason for this deviance worries scholars and indicates the ultimate need to search for suitable theories or models to curtail this behaviour.

Both in developing and developed countries, people now live longer than before. The reduction in birth and death rates has increased average life expectancy for contemporary societies. Since population ageing has now metamorphosed into a defining global issue, a conglomerate of intervention programmes and framework have emerged to cater for the health needs of the elderly population. Nigeria is one of the most populous countries in the world with a current estimated population of $187,327,179$. According to United Nation, the Nigerian population will reach 400 million by 2050. The elderly population has increased from $6,987,066$ in 2012 to $6,987,149$ in 2014 consisting $4 \%$ of the Nigerian population [11]. The average life expectancy was increase from 46 in 2009 to 54 in 2014 [11]. In the face of scare resources, this shift in demographic structure would adversely affect nations if approaches are not deployed to deal with the situation.

Nymphomania (excessive or uncontrolled sexual urge) is becoming a problem for people affected. This practice has promoted sexual promiscuity, sexual intercourse with multiple sex partners, infidelity in marriages and relationships and possibly unprotected sexual intercourse because of the uncontrolled urge with the quest and expectation of deriving sexual satisfaction. Since sex drive is innate as postulated by Sigmund Freud, the dynamics of exhibiting uncontrolled sexual desire have not been wellexplained with existing theories talk less of theorizing to subject the problem under control.

The increase rate of divorce in marriages has become another worrisome social phenomenon invading the marriage systems of different cultural and ethnic traditions in contemporary societies. With the increasing flamboyancy of marriage ceremonies, couples do not consider the cost before opting for a divorce. This situation differs from what is 
obtainable in the olden day where people marriage and stay together for as long as they have life. The shift in this respected norm and value pose a big challenge to scholars to understanding why and what approaches to proffer to resuscitate the respected norm in marriage. Though Max Weber has proposed "Verstehen" to understand the intention and context of man social behaviour and action, however, theorizing is highly needed to drastically minimize the occurrence of divorce.

The act of terrorism is another social problem that is widespread in virtually all facets of the world. Nigeria in particular is suffering in the hands of Boko Haram sectarian group and the Niger Delta militants group (now known as the Avengers). The gross conflict existing between the government and the masses constantly triggers this act. Consequently, aids from within and outside the country have been employed in tackling these problems. Though efforts so far seems promising, yet much more needs to be done. From the global perspective, the Isis and other terrorist groups are always on the news for one terrorist attack or the other. This particular problem has affected the economies of countries and has led to increase of internally displaced persons (IDPs), proliferation of refugee camps, spread of infections, widespread insecurity, food insecurity, loss of lives and properties. Insecurity as a whole is a general problem in all countries but that of Nigeria is very alarming probably because of the porousness of its security system. For instance, Calabar metropolis, a major city in Nigeria, was once known to be a safe, clean and green which encourage the influx of people from all works of life either for business or pleasure. This is not the case presently as the city has now metamorphosed into a den or hub for kidnappers, armed robbery, theft, vandalism of properties, killing/assassinations and organized group violence. The issue of insecurity has affected the economic sector of the city, state and country as a whole.

In the educational sector, there is a widespread incidence called "sorting syndrome" which has a deep-rooted strong hole in higher institutions. Lecturers discourage learning and hard work among students due to their indulgence in collection of bribes (especially money) in exchange for exam scores to enable lazy students pass their courses. Schools and institutions that encourage such practices without any penalty gradually debilitate the education value of the country. Theorists have to develop a model to first understand why the compromise on the part of lecturers, existence of anarchy in the educational system and its therapy to solve the problem.

The rivalry that exists in the health sector and health care facilities over superiority complex between health care professionals hampers the growth of the health care system in Nigeria. This issue has constantly attempted to fuel the policy of privatizing the health sector which many scholars tend to affirm to this view. The disadvantaged populace and poor patients may likely suffer if such policies emerge without a concrete framework to carter for their health needs. Theorists have a role to play in settling this dispute in the health sector.
Cultism and organized-group violence are subsidiaries of terrorist groups. These acts have invaded the higher institution as well as the political sphere. As a result, assassinations, killings and violence becomes the hobby of practitioners. Inspite of its danger, both the young and old still craves to belong to these organizations probably for the purpose of affluence, power, wealth and brotherhood/sisterhood association. Young girls as well as women engage in prostitution either for socio-economic reasons or as a source of pleasure and excitement. The practice of prostitution has attendant consequences on the health of these young girls. Some countries however, have legalized this practices and it has been encouraged to be a full-time employment for young girls. Based on this, solution to the aforementioned giant two problems is dependent on effective theorizing.

\section{Conclusion}

From the foregoing, there are several existing theories that provide explanation and understanding of the aetiology of health and social problems and their dynamism in occurrence. What is obviously lacking are problem-solving theories to provide lasting solution to these problems which existing theories cannot be applied. For new ideas, concepts, paradigms and theories to emerge, scholars must constantly engage in empirical research if contemporary issues, health and social problems are to be effectively controlled, prevented or eradicated in the future. This paper therefore recommends that theorists, scholars and researchers work symbiotically and synergistically to bring about stability, social equilibrium and positive change in the society.

\section{References}

[1] Etobe, E. I. (2005): Sociology of health and rehabilitation. Revised edition, De Arizona's publishers, pp. 41.

[2] Ottong, J. G. (2011): The study of sociology: A conceptual approach. Published in Nigeria by University of Calabar Printing \& Publishing Press. pp 299.

[3] Gupta, P., Anjum, F., Bhardwaj, P., Srivastav, J. P., \& Zaidi, Z. H. (2013): Knowledge About HIV/AIDS Among Secondary School Students. N Am J Med Sci; 5(2): 119-123.

[4] Ebor, M, Murray, A, Gaul, Z, \& Sutton, M. (2015): HIV Awareness and Knowledge among Viewers of a Documentary Film about HIV among Racial- or Ethnic-Minority Older Adults. Health Soc Work; 40(3):217-24.

[5] National Malaria Strategic Plan 2014-2020. Retrieved from ihi.eprints.org/3314/.../Malaria_Strategic_Plan_Full_Version_ $02 \quad 27 \quad 14$.

[6] Nigeria International Diabetes Federation. Retrieved from: http://www.idf.org/membership/afr/nigeria.

[7] Ogbera, A. O., \& Ekpebegh, C. (2014): Diabetes mellitus in Nigeria: The past, present and future. World J Diabetes; 5(6): 905-911. 
[8] Pharmanews (2016): World Cancer Day 2016: How to reduce cancer burden in Nigeria. Published On: Wed, Feb 3rd, 2016. Edition: vol. 38 N0.

8http://www.pharmanewsonline.com/world-cancer-day-2016how-to-reduce-cancer-burden-in-nigeria/.

[9] Ekine, A. A., Lawani, L. O., Iyoke, C. A., Jeremiah, I., \& Ibrahim, I. A. (2015): "Review of the Clinical Presentation of Uterine Fibroid and the Effect of Therapeutic Intervention on
Fertility." American Journal of Clinical Medicine Research 3 (1): 9-13.

[10] Ogedengbe, O. K. (2003): Uterine Fibroids In: Contemporary obstetrics and gynaecology for developing countries. Okonofua. F and Odunsi K (Ed) Intec printers limited Ibadan. Pg 202-213.

[11] National Bureau of Statistics (2016): Statistical Report on Men and Women in Nigeria. 